\title{
Controlled atmosphere pallets to extend the shelf- life of Calanda peaches
}

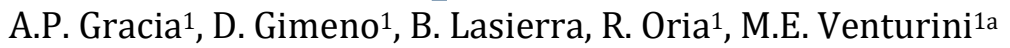 \\ ${ }_{1}$ Plant Food Research Group. Instituto Agroalimentario de Aragón- IA2 -(Universidad de \\ Zaragoza-CITA), Miguel Servet, 177. 50013, Spain.
}

\begin{abstract}
Calanda peaches have achieved great prestige in European markets because of its size, firmness and sweetness. However, apart from maintaining current markets by offering a high-quality product, further research is needed to improve their shelf life in order to reach more distant markets. Thus, the effects of controlled atmosphere (CA) pallets $\left(\mathrm{O}_{2}-\mathrm{CO}_{2}\right.$ concentrations, $10 \%-10 \%, 5 \%-10 \%$ and $\left.2 \%-10 \%\right)$ in the quality and shelf-life of Calanda peaches cv. Calante have been studied. Physico-chemical parameters, ethanol and acetaldehyde production, percentage of diseases, chilling injury development and sensory evaluation were determined every 15 days until the end of the shelf-life. Also, gas chromatography-olfactometry was conducted to detect off-flavours.

Peaches stored in an air atmosphere at $1{ }^{\circ} \mathrm{C}$ promptly developed symptoms of chilling injury that became severe on day 28 . All the CA conditions delayed ripening and prevent chilling injury, being the peaches stored in $2 \% \mathrm{O}_{2}-10 \% \mathrm{CO}_{2}$ the best rated in the sensory evaluation. Although an increase in the production of ethanol and acetaldehyde was detected from day 14 onwards, this did not affect the quality of the fruit that was excellent after 56 days at $1^{\circ} \mathrm{C}$ plus a shelf-life period of 2 days at $20^{\circ} \mathrm{C}$.
\end{abstract}

Keywords: controlled atmosphere, storage, shelf-life, GC-O, Calanda peach, Prunus persica

\section{INTRODUCTION}

Peach (Prunus persica L. Batsch) is a climacteric stone fruit species originated from China, and it can provide high nutrition and a pleasant flavor (Lyu et al., 2015). "Calanda Peach" is the fruit commercialized under the stamp of the Regulating Council, belonging to the native cultivar 'Late Yellow' and their clones 'Jesca', 'Evaisa' and 'Calante'. Calanda peach has achieved great prestige in the market due to its large size, firmness, flavour and sweetness.

Peach fruit has a short shelf-life potential due to fast softening and overall ripening (Lyu et al., 2015). The ISO International Standard for peaches states that optimum storage temperature for peaches is -1 to $+2^{\circ} \mathrm{C}$, and a storage life of only $2-4$ weeks. Thus, it is necessary to determine the best transport and distribution conditions in order to export the product with the maximum quality to far countries such China, USA or South America.

Cold storage not always succeed in maintaining fruit quality during the commercialization. Thus, atmosphere modifications and a strict relative humidity control are necessary to optimize the transport and distribution. Controlled atmosphere pallets allows us to set the desired $\mathrm{O}_{2}$ and $\mathrm{CO}_{2}$ compositions in individual pallets by creating CA conditions (Selcuk and Erkan, 2015).

aE-mail: ugeventu@unizar.es 
They are suitable for short and long-term storage under CA and ultra-low oxygen (ULO) conditions and the high gas tightness of the plastic cover allows an optimum control of the gas and humidity conditions.

\section{MATERIALS AND METHODS}

\section{Plant material and storage conditions}

This research was carried out with Calanda peaches cv. Calante. The fruit was collected the third week of October 2016 in Caspe (Zaragoza, Spain). The selected fruits were packed in wooden boxes with plastic socket and were transported under refrigerated conditions to the storage points. The peaches were divided into 4 homogeneous batches. Control batch (CB) was kept in a conventional refrigeration chamber at $1{ }^{\circ} \mathrm{C}$ and with relative humidity control $(85 \% \mathrm{RH})$. The other 3 batches were kept in refrigeration chambers at $1{ }^{\circ} \mathrm{C}$ equipped with controlled atmosphere pallets (CAP) under different concentrations of oxygen and carbon dioxide (CA-1: $10 \% \mathrm{O}_{2} / 10 \% \mathrm{CO}_{2}$; CA-2: $5 \% \mathrm{O}_{2}$ and $10 \% \mathrm{CO}_{2}$; CA-3: $2 \% \mathrm{O}_{2}$ and $10 \% \mathrm{CO}_{2}$ ).

\section{Ethanol-acetaldehyde determination.}

For the determination of ethanol and acetaldehyde, an adaptation to the method described by Gorny et al. (1999) was made. For this, $20 \mathrm{~mL}$ of peach juice was transferred to a 100-mL test tube, fitted with a silicone septum to allow the extraction of samples from the headspace. The tubes were incubated in a water bath at $60^{\circ} \mathrm{C}$ for one hour. One $\mathrm{mL}$ of each sample was injected from the headspace of the vials by a Hamilton 1001RN gastight syringe on a Hewlett Packard 4890 gas chromatograph equipped with a flame ionization detector. An HP 19001A-QSO column was used. The analysis time was 7 minutes under isothermal conditions, with the oven at $50{ }^{\circ} \mathrm{C}$, the detector at $125{ }^{\circ} \mathrm{C}$ and the injector at $50{ }^{\circ} \mathrm{C}$. $\mathrm{N}_{2}$ was used as carrier gas, and the head pressures were: $\mathrm{N}_{2} 50$ psi, $\mathrm{H}_{2} 20$ psi, 42 psi air. For the identification of the chromatographic peaks, as well as for the quantification, different concentrations of analytical grade ethanol and acetaldehyde were used, obtaining the standard curves. This analysis was performed in duplicate for each control point.

\section{Skin colour}

External skin colour was measured on 20 fruit from each batch with a colorimeter (Konica Minolta, Chroma meter CR-400, Japan). Two measurements on the equatorial region of each peach were made. The values of the coordinates $L^{*}, a^{*}, b^{*}$ and $C^{*}$ were obtained. Differences with the initial sample were calculated with the above parameters from the following equation:

$$
\Delta \mathrm{E}=\sqrt{ }\left(\Delta \mathrm{a}^{2}+\Delta \mathrm{b}^{2}+\Delta \mathrm{L}^{2}\right)=\sqrt{ }\left(\mathrm{a}^{*} \mathrm{~m}-\mathrm{a}^{*} \mathrm{ref}\right)^{2}+\left(\mathrm{b}^{*} \mathrm{~m}-\mathrm{b}^{*} \mathrm{ref}\right)^{2}+\left(\mathrm{L}^{*} \mathrm{~m}-\mathrm{L}^{*} \mathrm{ref}\right)^{2}
$$

$\Delta \mathrm{E}<3$ : no appreciable colour differences between the two samples.

$\Delta \mathrm{E}>3$ : the colour differences between the two samples are appreciable by the human eye.

\section{Chilling injury}

Characterization of the severity of chilling injury was made by quantifying the internal browning. Based on these values, and with the sensory appreciation of other symptoms, such as wooliness and texture, a score for chilling injuries was established. To determine these values, the peach was divided into two equal parts, observing clearly the pulp and the stone. Internal browning consists of measuring the percentage of browning surface that appears in the peach pulp. This darkening usually appears around the bone and diffuses outwards. To quantify it, arbitrary values were assigned according to a scale from 0 to 5 (Figure 1). 


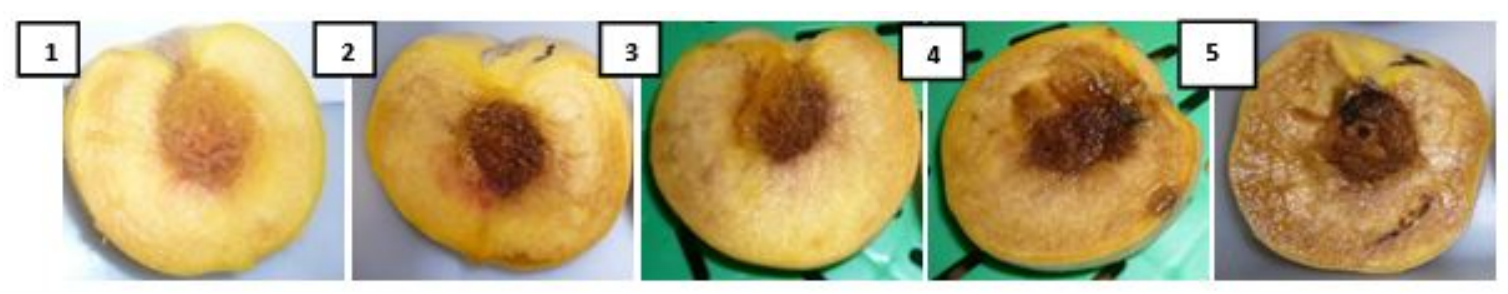

Figure 1: Scale for the quantification of chilling injuries (order from grade 1 (very light) to grade 5 (very severe).

\section{Analysis of aroma compounds}

1. Solid-phase microextraction (SPME) of aroma compounds

To perform the analysis, a SPME holder provided with a silica fibre coated with a 50/30 $\mathrm{mm}$ layer of divinylbenzene/carboxen/polydimethylsiloxane from Supelco (Barcelona, Spain) was used to extract the aroma compounds. Seven $\mathrm{mL}$ of peach puree was placed in a glass vial of $20 \mathrm{~mL}$ and closed with a septum. The sample was conditioned at $50^{\circ} \mathrm{C}$ for $20 \mathrm{~min}$. Then, the fibre was exposed to the headspace of the sample for $40 \mathrm{~min}$. After sampling, the GC-O analysis was carried out immediately. Five SPME extracts were prepared, one per GC-O judge.

\section{Gas chromatography-olfactometry}

The analysis of aroma compounds was carried out in a gas chromatograph HP 4890 (Termoquest, Milan, Italy) with a flame ionization detector (FID) and sniffing port (ODO-1 by SGE). The chromatograph was provided with a capillary column DB-WAX of $30 \mathrm{~m}, 0.32 \mathrm{~mm}$ i.d., $0.5 \mathrm{~mm}$ film thickness, and a precolumn ( $3 \mathrm{~m}$; $0.32 \mathrm{~mm}$ i.d.) from Supelco (Bellefonte, PA). Nitrogen was a carrier ( $\left.3.5 \mathrm{~mL} \mathrm{~min}^{-1}\right)$; splitless injection (splitless time $60 \mathrm{~s}$ ); injector and detector temperature $220^{\circ} \mathrm{C}$. The oven temperature was set at $40^{\circ} \mathrm{C}$ for $5 \mathrm{~min}$, and then increased $6^{\circ} \mathrm{C} \mathrm{min}-1$ until reach $220^{\circ} \mathrm{C}$. Five sniffers provided the descriptors of each odorant detected. The scale used to assess the intensity of each eluted odor in the capillary column was composed of 3 principal points $(1=$ low intensity, $2=$ strong intensity, $3=$ extremely strong intensity) and 3 intermediate values $(0.5,1.5$ and 2.5$)$ Data were processed as modified frequency (MF), following the methodology used by Campo et al. (2017) and proposed by Dravnieks (1985). The aroma compounds were identified comparing with pure reference compounds and their retention index in a DB-WAX column. Furthermore, the results were checked by published bibliography.

\section{Sensory analysis}

Sensory analysis was carried out by a panel of trained experts formed by members of the Plant Food Research Group. The purpose of this analysis was to evaluate the appearance and organoleptic quality of Calanda DOP peaches. This analysis included three phases: visual (skin colour, defects/hits and hedonic preference), tactile (firmness) and gustative phase.

\section{RESULTS AND DISCUSSION}

\section{Ethanol-acetaldehyde determination}

Ethanol-acetaldehyde determination was carried out to check if the increase in the $\mathrm{CO}_{2}$ content $(10 \%)$ and the decrease in the concentration of $\mathrm{O}_{2}$ stimulated the accumulation of these compounds in the fruits and therefore the development of anomalous flavours. The production of ethanol and acetaldehyde was detected in the 4 storage conditions and at all points of analysis being more evident and fast in the control batch and occurred more slowly in the batches stored in controlled atmospheres, especially in that with the lowest percentage of oxygen (CA-3). 
A)

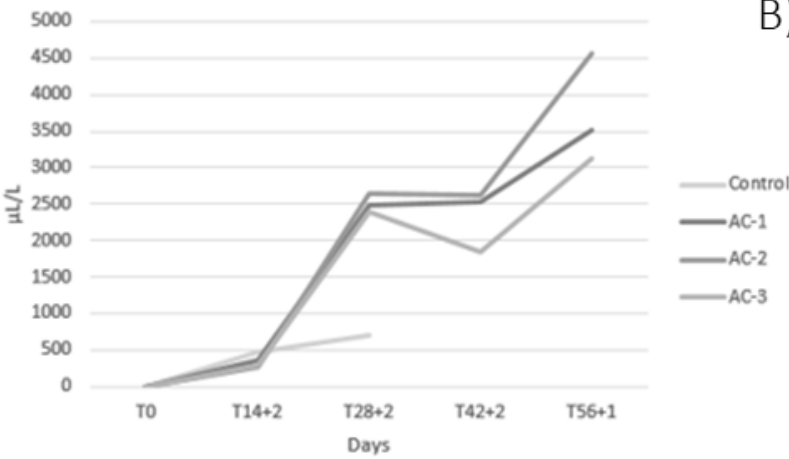

B)

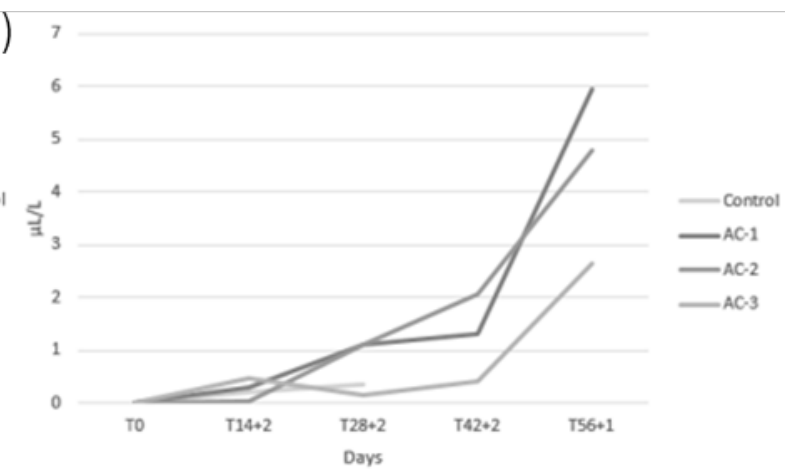

Figure 2: Ethanol (A) and acetaldehyde (B) $(\mu \mathrm{l} / \mathrm{L}))$ in Calanda peaches stored at 1을 ${ }^{\circ} \mathrm{C}$ air (control), $10 \% \mathrm{O}_{2}+10 \% \mathrm{CO}_{2}$ (AC-1), $5 \% \mathrm{O}_{2}+10 \% \mathrm{CO}_{2}$ (AC 2 ) y $2 \% \mathrm{O}_{2}+10 \% \mathrm{CO}_{2}$ (AC-3). After marketing simulation periods.

\section{Skin Colour}

In peaches, the colour coordinate $\mathrm{a}$ * normally increases throughout storage and the coordinate $\mathrm{b}$ * increases during the first stages of storage and then decreases-If we calculate the colour variation $(\Delta \mathrm{E})$ from day 0 to the different storage days we observed that all the fruit batches varied their colour $(\Delta \mathrm{E}>3)$ and that this variation occurred earlier in the control batch with a $\Delta \mathrm{E}$ of 13 on day 28 (Table 1 ).

Table 1. Colour evolution in Calanda peaches stored at $1^{\circ} \mathrm{C}$ : air (control), $10 \% \mathrm{O}_{2}+10 \% \mathrm{CO}_{2}(\mathrm{AC}-1), 5 \% \mathrm{O}_{2}+10 \% \mathrm{CO}_{2}$ (AC-2) y $2 \% \mathrm{O}_{2}+10 \% \mathrm{CO}_{2}$ (AC-3). After cold storage and after marketing simulation periods.

\begin{tabular}{ccccc}
\hline & CONTROL & AC-1 & AC-2 & AC-3 \\
T14 & 3,9464 & 7,7971 & 7,0108 & 6,5198 \\
T14+2 & 6,8175 & 5,9911 & 4,9677 & 5,4407 \\
T28 & 13,881 & 8,3569 & 6,4079 & 8,1652 \\
T28+2 & 10,205 & 7,1903 & 5,4947 & 5,7410 \\
T42 & & 8,1332 & 6,6144 & 6,7722 \\
T42+2 & & 4,1259 & 7,7077 & 7,1617 \\
T56 & & 8,3181 & 9,3651 & 7,1277 \\
T56+1 & & 8,72891 & 5,7776 & 5,5994 \\
\hline
\end{tabular}

\section{Chilling injuries}

Late peach cultivars, such as Calanda, are more sensitive to suffer chilling injury (Mitchell et al., 1976; Von Mollendorf, 1987; Ben-Arie and Lavee, 1971). Shelf-life of Calanda peaches stored in an air atmosphere ended on day 14, since on day 28 all the fruits were affected by a severe chilling injury (Figure 3). However, the fruits preserved in controlled atmospheres did not show any physiological disorder during the cold storage or after the marketing simulation periods. 


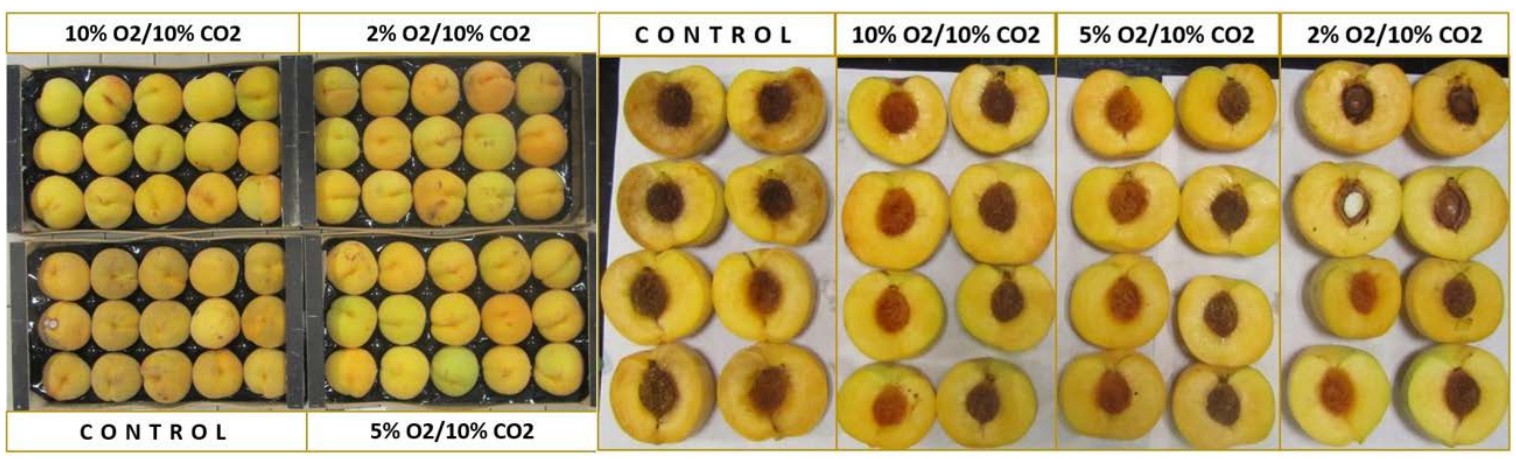

Figure 3: Calanda peaches stored at $1{ }^{\circ} \mathrm{C}$ in air (control), in modified atmosphere $10 \% \mathrm{O}_{2}+$ $10 \% \mathrm{CO}_{2}(\mathrm{AC}-1), 5 \% \mathrm{O}_{2}+10 \% \mathrm{CO}_{2}(\mathrm{AC}-2)$ and $\left.2 \% \mathrm{O}_{2}+10 \% \mathrm{CO}_{2}(\mathrm{AC}-3)\right)$ after 28 days.

\section{Analysis of aroma compounds}

In the olfactometry analysis, a total of 21 odorant zones were detected, of which 18 could be identified. Peaches showed a complex aromatic profile formed by compounds of different families such as aldehydes, ketones, alcohols and ethyl esters (Table 2).

Seven odorant zones were common for all the analyzed samples and all were identified. An ethyl ester (ethyl 2-methylbutyrate) described as dairy and detected at $10.40 \mathrm{~min}$. Three areas described with Green-grass/Sweet-green and fish aromas were represented by four aldehydes; Hexanal (11.58 min), Z-3-hexenal (13.53 min), T-2-hexenal (16.43 min) (Bavcon Kralj et al., 2014) and Z-4-heptenal (17.26 min). Sweet green apple scent was described to identify 1-butanol (14.08 min). Finally, a ketone (Z-1,5-octadien-3-one), described with a geranium aroma, was detected at 21.51 minutes.

The aroma components widely varied throughout the storage time. The rest of the total odorant zones detected (14) play an important role in the changes of aroma of the fruits during the whole period of study. Of the 14 odorant zones detected, 11 could be identified. Two odorant compounds only appeared at first point of analysis, Ethyl-4-methylpentanoate and 3-isopropyl-2-methoxypyrazine (15.42 $\mathrm{min}$ and $23.37 \mathrm{~min}$ respectively). At the end of the storage, 2,3-butanodione (compound with dairy-strawberry flavor) does not appear in AC-1 and AC-2 samples. It is noteworthy the presence of dimethylsulphide (5.32 min), described like dark chocolate, in the control batch at the last point of analysis and at all points of analysis in AC-2 and AC-3. 2-butanol appeared in all samples (except at T0) with similar MF values, so the presence of this aroma cannot be attributed to the use of CA. Is important to emphasize the presence of 1-octen-3-one (mushroom aroma), an oxidation compound that appear from 14 days onwards. Other oxidation aroma compound that appeared was produced by methional (cooked potato), detected at 24.28 minutes.

The use of the different atmospheres tested in this study made disappear pleasant aromas and appear off-flavors, but their use also led to the appearance of fresh fruity aromas, as ethyl isovalerate $(11,15 \mathrm{~min})$, whose development was detected with more intensity in AC2 and AC-3. 
Table 2. Evolution of odorant compounds in Calanda peaches conserved at $1 \stackrel{\circ}{\circ} \mathrm{C}$ : air (control), $10 \% \mathrm{O}_{2}+10 \% \mathrm{CO}_{2}(\mathrm{AC}-1), 5 \% \mathrm{O}_{2}+10 \% \mathrm{CO}_{2}(\mathrm{AC}-2)$ y 2 $\% \mathrm{O}_{2}+10 \% \mathrm{CO}_{2}(\mathrm{AC}-3)$.

\begin{tabular}{|c|c|c|c|c|c|c|c|c|c|c|c|}
\hline \multirow{3}{*}{$\begin{array}{c}\text { LIR } \\
\text { DBWAX } \\
<1000\end{array}$} & \multirow[b]{2}{*}{$\underset{(\min )}{\operatorname{Tm}}$} & \multirow[b]{2}{*}{ Identity } & \multirow[b]{2}{*}{ Odour descriptor } & \multicolumn{2}{|c|}{ CONTROL } & \multicolumn{2}{|c|}{ AC-1 } & \multicolumn{2}{|c|}{$A C-2$} & \multicolumn{2}{|c|}{$A C-3$} \\
\hline & & & & MF TO & MF T28 & MF T28 & MF T56 & MF T28 & MF T56 & MF T28 & MF T56 \\
\hline & 5,32 & Dimetilsulfide & Dark chocolate & n.d & 41 & n.d & n.d & 41 & 50 & 55 & 50 \\
\hline 1016 & 9,38 & 2-butanol & Solvent & n.d & 66 & 65 & 50 & 67 & 61 & 53 & 66 \\
\hline 1031 & 10,06 & Ethyl butyrate & Fruity & 45 & 50 & 55 & 50 & n.d & 67 & n.d & 83 \\
\hline 1049 & 10,40 & Ethyl-2-Methylbutyrate & Dairy & 71 & 69 & 69 & 61 & 50 & 71 & 69 & 51 \\
\hline 1074 & 11,26 & u.i & Solvent & 58 & n.d & n.d & n.d & n.d & n.d & n.d & n.d \\
\hline 1091 & 11,58 & Hexanal & Green & 50 & 65 & 69 & 33 & 67 & 75 & 67 & 51 \\
\hline 1118 & 12,53 & $u . i$ & Vanilla- coconut & n.d & n.d & n.d & 69 & n.d & n.d & n.d & n.d \\
\hline 1147 & 13,53 & (Z)-3-hexenal & Green-grass & 85 & 41 & 43 & 42 & 59 & 49 & 67 & 50 \\
\hline 1154 & 14,08 & 1-butanol & Sweet green apple & 56 & 75 & 75 & 57 & 75 & 59 & 83 & 75 \\
\hline 1316 & 19,30 & u.i & Flowery & n.d & n.d & n.d & 35 & n.d & n.d & n.d & n.d \\
\hline 1318 & 19,31 & 1-octen-3-one & Mushroom & n.d & 67 & 66 & 67 & 59 & 55 & 41 & 67 \\
\hline 1392 & 21,51 & (Z)-1,5-octadien-3-one & Geranium & 60 & 83 & 85 & 59 & 85 & 82 & 66 & 67 \\
\hline 1453 & 23,37 & 3-isopropyl-2-methoxypyrazine & Tomato & 41 & n.d & n.d & n.d & n.d & n.d & n.d & n.d \\
\hline 1482 & 24,28 & Methional & Cooked -potato & n.d & 33 & 39 & n.d & 33 & n.d & n.d & 50 \\
\hline
\end{tabular}

n.d: Not detected / $\mathrm{n}$.i: not identified 


\section{Sensory analysis}

Sensory evaluation was only performed after the marketing simulation periods. First of all, it should be indicated that all the peaches analysed had yellow to straw yellow skin colour, which is the colour required by the DOP Calanda Peach to label the fruits as "Calanda Black Peach Label".

Even though the taste preference values (characteristic flavor) were diminished by the tasting panel, none of them detected the presence of off-flavours in the fruits at any of the points of analysis even AC 3 was the atmosphere with the less oxygen content. This indicates that the fruits did not show evidence of having entered into the fermentative process. Firmness and crispness data were kept stable during storage, obtaining high scores $(\sim 4)$.

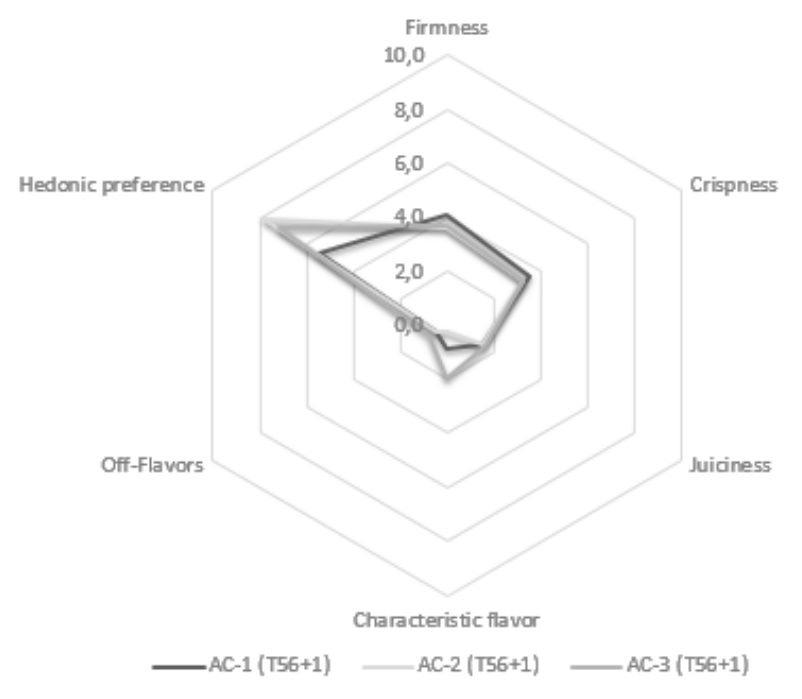

Figure 4: Sensory evaluation of Calanda peaches conserved at $1^{\circ} \mathrm{C}$ at last point of analysis: $10 \% \mathrm{O}_{2}+10 \% \mathrm{CO}_{2}(\mathrm{AC}-1), 5 \% \mathrm{O}_{2}+10 \% \mathrm{CO}_{2}(\mathrm{AC}-2)$ and $2 \% \mathrm{O}_{2}+10 \% \mathrm{CO}_{2}(\mathrm{AC}-3)$

At the end of the storage, the fruit with the best scores were those of the batches with the lowest oxygen contents ( 5 and $2 \%$ ) in which attributes such as firmness, crispness and juiciness were scored with values very close to the maximum ones.

\section{CONCLUSIONS}

All the controlled atmosphere conditions tested $\left(\mathrm{O}_{2}-\mathrm{CO}_{2}, 10 \%-10 \%, 5 \%-10 \%\right.$ and $2 \%-10 \%)$ prolong the storage time of Calanda peach cv. Calante, without affecting its physicochemical or sensorial quality and minimizing the appearance of chilling injury.

\section{Literature cited}

Bavcon Kralj, M., Jug, T., Komel, E., Fajt, N., Jarni, K., Zivkovic, J., Mujic, I., and Trutic, N. (2014). Effects of ripening degree and sample preparation on peach aroma profile characterization by headspace solid-phase microextraction. Turkish Journal of Agriculture and Forestry. 38, 676-687 10.3906/tar-1307-129.

Ben-Arie, R. and Lavee, S. (1971). Pectic changes occurring in 'Elberta' peaches suffering from woolly breackdown, Phytochem, 19, 2553-2555. 10.1016/S0031-9422(00)94693-4

Campo, E., Marco, P., Oria, R., Blanco, D., and Venturini, M.E. (2017). What is the best method for preserving the genuine black truffle (Tuber melanosporum aroma? An olfactometric and sensry aproach. Food Science and Technology, 80, 84-91. 10.1016/j.lwt.2017.02.009 
Dravnieks, A. (1985) Atlas of odour profiles (p.354). Philadelphia, PA.

Gorny, J. R., Hess-Pierce, B. y Kader, A. A. 1999. Quality changes in fresh-cut peach and nectarine slices as affected by cultivar, storage atmosphere and chemical treatments. Jour. Food Scie., 64, 429-432. 10.1111/j.13652621.1999.tb15057.x

International Organization for Standardization (1980) International Standard, Peaches-Guide to cold storage, ISO 873-1980(E)

Lyu, J., Zhou, L.Y., Bi, J.F., Liu, X., and Wu, X.Y. (2015). Quality evaluation of yellow peach chips prepared by explosion puffing drying. Journal of Food Science and Technology-Mysore. 52, 8204-8211. 10.1007/s13197-0151906-0

Mitchell, F.G. (1987). Influence of cooling and temperature maintenance on the quality of California grown stone fruit. International Journal Refrigeration, 10, 77-81. 10.1016/0140-7007(87)90024-7

Selcuk, N., and Erkan, M. (2015). The effects of modified and palliflex controlled atmosphere storage on postharvest quality and composition of 'Istanbul' medlar fruit. Postharvest Biology and Technology. 99, 9-19 10.1016/j.postharvbio.2014.07.004

Von Mollendorff, L.J. (1987). Wollines in peaches and nectarines: 1. Maturity and external factors. Horticultural Science, 5, 1-3. 